\title{
Integrating time-series SAR data and ORYZA crop growth model in Rice area mapping and yield estimation for crop insurances
}

\author{
*S. Pazhanivelan ${ }^{1}$, K.P. Ragunath ${ }^{1}$, N.S. Sudarmanian ${ }^{1}$, R. Kumaraperumal ${ }^{1}$, Tri Setiyono ${ }^{2}$ and E.D. Quicho ${ }^{2}$ \\ ${ }^{1}$ Department of Remote Sensing and GIS, Tamil Nadu Agricultural University, Coimbatore, Tamil Nadu, India - \\ ragunathkp@gmail.com, sudarnsagri@gmail.com, kumaraperumal.r@gmail.com, \\ ${ }^{2}$ International Rice Research Institute, Philippines - t.setiyono@irri.org, e.quicho@irri.org \\ *Corresponding author E-mail: pazhanivelans@gmail.com.
}

Commission III, WG III/10

KEY WORDS: Rice, Crop yield estimation, Synthetic Aperture Radar (SAR), Sentinel 1A, Crop growth model, ORYZA2000, Crop insurance

\begin{abstract}
:
Lowland rice in tropical and subtropical regions can be detected precisely and its crop growth can be tracked effectively through Synthetic Aperture Radar (SAR) imagery, especially where cloud cover restricts the use of optical imagery. Parameterised classification with multi-temporal features derived from regularly acquired, C-band, VV and VH polarized Sentinel-1A SAR imagery was used for mapping rice area. A fully automated processing chain in MAPscape-Rice software was used to convert the multi-temporal SAR data into terrain-geocoded $\sigma^{\circ}$ values, which included strip mosaicking, co-registration of images acquired with the same observation geometry and mode, time-series speckle filtering, terrain geocoding, radiometric calibration and normalization. Further Anisotropic non-linear diffusion (ANLD) filtering was done to smoothen homogeneous targets, while enhancing the difference between neighbouring areas. Multi-Temporal Features viz., max, min, mean, max date, min date and span ratio were extracted from VV and VH polarizations to classify rice pixels. Rice detection was based on the analysis of temporal signature from SAR backscatter in relation to crop stages. About sixty images across four footprints covering 16 samba (Rabi) rice growing districts of Tamil Nadu, India were obtained between August 2017 and January2018. In-season site visits were conducted across 280 monitoring locations in the footprints for classification purposes and more than 1665 field observations were made for accuracy assessment. A total rice area of 1.07 million ha was mapped with classification accuracy from 90.3 to 94.2 per cent with Kappa values ranging from 0.81 to 0.88 . Using ORYZA2000, a weather driven process based crop growth simulation model developed by IRRI, yield estimates were made by integrating remote sensing products viz., seasonal rice area, start of season and backscatter time series. By generating average backscatter for each time series and $\mathrm{dB}$ stack for each SoS, LAI values were estimated. The model has generated rice yield estimate for each hectare which were aggregated at administrative boundary level and compared against CCE yield. Yield Simulation accuracy of more than 86-91\% at district level and $82-97 \%$ at block level from the study indicates the suitability of these products for policy decisions. SAR products and yield information were used to meet the requirements of PMFBY crop insurance scheme in Tamil Nadu and helped in identifying or invoking prevented/failed sowing in 529 villages and total crop failure in 821 villages. In total 303703 farmers were benefitted by this technology in getting payouts of INR 9.94 billion through crop insurance. The satellite technology as an operational service has helped in getting quicker payouts.
\end{abstract}

\section{INTRODUCTION}

Monitoring production of field crops is important for ensuring food security in India. Accurate and consistent information on the area under production is necessary for national and state planning but conventional statistical methods cannot always meet the requirements. This information is vital to the policy decisions related to imports, exports and prices, which directly influence food security. Fluctuation in domestic rice production has a significant impact on household food security.

Satellite-based remote sensing offers a suitable and costeffective technique needed for regional- and national-scale crop monitoring by allowing retrieval of spatially distributed information on a large scale (Gumma et al. 2014). The use of remote sensing data for crop yield estimation has been demonstrated with reasonable success based on optical satellite remote sensing data from Landsat under European-type climate (Ferencz et al. 2004). However, in the context of rice in Asia, cloud cover is extensive and pervasive during the key crop growing season (Huke and Huke 1997) and therefore presents a critical obstacle for implementing satellite-based remote sensing techniques for crop monitoring. Radar-based remote sensing, for example, Synthetic aperture radar (SAR), provides a comparative advantage with its cloud-penetrating characteristics (Dwivedi, Rao, and Kushwaha 2000). Le Toan et al. (1997) demonstrated the application of C-band SAR data from RADARSAT for rice area mapping in experimental settings in Japan and Indonesia capturing longduration temperate rice and short-duration tropical rice, respectively. Likewise, others have documented the suitability of SAR for rice area mapping (Suga and Konishi 2008; Bouvet, Le Toan, and Lam-Dao 2009; Oh et al. 2009; Lopez-Sanchez, Ballester-Berman, and Hajnsek 2011; Inoue and Sakaiya 2013; Inoue, Sakaiya, and Wang 2014). Whereas these studies focused on a limited number of observation locations and thus limited scalability, Nelson et al. (2014) demonstrated an operational-orientated effort with extensive demonstration of rice area mapping with SAR in 13 geographical rice-growing locations across South and South-east Asia in the context of the 
Remote Sensing-based Information and Insurance for Crops in Emerging economies (RIICE) project (www.riice.org).

Similar to the experience of rice area mapping, yield estimation using SAR has been documented, including the integration of SAR with a crop growth model (Homma, Maki, and Hirooka 2017; Maki et al. 2017). However, these studies involved very limited quality assessment. Ferencz et al. (2004) simulated crop yield without the use of a process based crop growth model by empirically linking optical remote sensing data to crop yield. This approach has the advantage of high processing efficiency for mapping context compared with the option of making computing-intensive yield simulation runs with a process-based crop growth model. The wide range of agronomic practises and environments in which the rice crop is grown poses a significant challenge to the option of using an empirical approach to estimate yield by directly exploiting remote sensing data alone without considering climate and other factors. Based on the accuracies obtained, over large area of TamilNadu, India, in rice mapping using rule based algorithm of MAPscape-RICE (Nelson et al., 2014) and yield estimation integrating SAR products and ORYZA crop growth model, this article presents the potential of Remote Sensing based products as an operational service in crop insurances.

\section{METHODS}

\section{Pre-Processing of SAR data}

A fully automated processing chain developed by Holecz et al. (2013) was used to convert SAR GRD multi-temporal data to terrain geo-coded $\sigma^{\circ}$ values. The processing chain itself is a module within the MAPscape-RICE software. The basic processing chain included strip mosaicking, co-registration of images acquired with the same observation geometry and mode, time-series speckle filtering, terrain geocoding, radiometric calibration and normalization. Further Anisotropic non-linear diffusion (ANLD) filtering was done to smoothen homogeneous targets, while enhancing the difference between neighbouring areas. Removal of atmospheric attenuation $-\sigma^{\circ}$ values was corrected by means of an interpolator.

\section{Multi-Temporal $\sigma^{\circ}$ Rule-Based Rice Detection}

The multi-temporal stack of terrain-geocoded $\sigma^{\circ}$ images was input to a rule-based rice detection algorithm in MAPscapeRICE. The temporal evolution of $\sigma^{\circ}$ is analyzed from an agronomic perspective, which also requires a priori knowledge of rice maturity, calendar and duration and crop practices from field information and knowledge of the study location. The temporal signature is frequency and polarization dependent and also depends on the crop establishment method and, to some extent, on crop maturity. This implies that general rules can be applied to detect rice, but that the parameters for these rules may need to be adapted according to the agro-ecological zone, crop practices and rice calendar.

\section{Use of Temporal Features to Guide Parameter Selection for the Rule-Based Classifier}

The choice of parameters was guided by a simple statistical analysis of the temporal signature of $\sigma^{\circ}$ values in the monitored fields. The mean, minimum, maximum, minimum ratio, maximum ratio and span ratio of $\sigma^{\circ}$ were computed for the temporal signature of each monitored field. These six statistics, called as temporal features, concisely characterize the key information in the rice signatures of the observed fields, and each one relates directly to one parameter. Hence, the values of the six temporal features from the monitoring locations were used to guide the classification.

\section{Rice Map Accuracy Assessment}

A standard confusion matrix was applied to the rice/non-rice validation points collected at each site. The overall accuracy of the rice/non-rice classification and the kappa value were recorded. The accuracy assessment is a comparison of the classified rice map against ground-truth data. To account for the lower resolution and the horizontal accuracy of the handheld GPS units relative to the pixel size, the validation data were collected in areas that had homogeneous land cover in a $50 \mathrm{~m}$ radius. The observed land cover at the GPS validation points was compared to the mode value of the rice map pixels within a window that matched the radius used in the validation land cover assessment.

\section{Yield simulation and mapping}

Rice-YES interface developed by IRRI, assimilates key SAR products, namely, LAI and SOS, into ORYZA in order to generate a map of yield estimates. The software consolidates all the inputs required to run ORYZA and run each combination of geo-referenced pixels according to the LAI values derived from SAR and other spatial inputs, including weather and soil information. The assimilation of SAR products begins after at least four SAR images have been acquired after the onset of the rice-growing season in the area (land preparation). Beginning 40 days after crop establishment, SAR product assimilation into the crop forecasting system is implemented. During this early part of the rice-growing cycle, leaf expansion parameters can be effectively calibrated against real ground conditions inferred from satellite observations using radar technology.

\section{RESULTS AND DISCUSSION}

\section{Rice Area Map}

Rice area map derived from multi-temporal C-band SAR imagery of Sentinel 1A for Cauvery delta Districts of TamilNadu, India during 2017-18 is presented in Fig.1. Late rice and early rice were combined into one class and distinguished from rice class in the map. Map accuracy considered any of the three rice subclasses as rice. In Total, a rice area of 1.072 million ha was mapped in 16 districts of TamilNadu covering 11259 villages. In-season site visits were conducted across 280 monitoring locations in the footprints for classification purposes and more than 1665 field observations were made for accuracy assessment. The accuracy assessment for the rice maps was conducted on a rice/non-rice basis, where all other land cover types were grouped into a single non-rice 
class. Accuracy assessments in the field were conducted inseason, in the reproductive or ripening stage before harvesting. Rice areas in different districts were mapped with classification accuracy ranging from 90.3 to 94.2 per cent with a Kappa value of 0.81 to 0.88 (Table 1 ).

\section{Start of the Season}

The time series of images used to estimate, the start date of the growing season for each pixel. This is a critical input to the crop model that estimates yield. It is also critical for estimating the area that has been planted at a given date. The start of the season map indicating the progress of planting / sowing in the study area is presented in Fig.2. The start of the season map indicated that, September to October was the peak season of planting coinciding with the onset of monsoon and release of water from Mettur dam. However, the planting during 2017-18 was delayed upto November in Cauvery delta districts due to late release of water (Table 2)

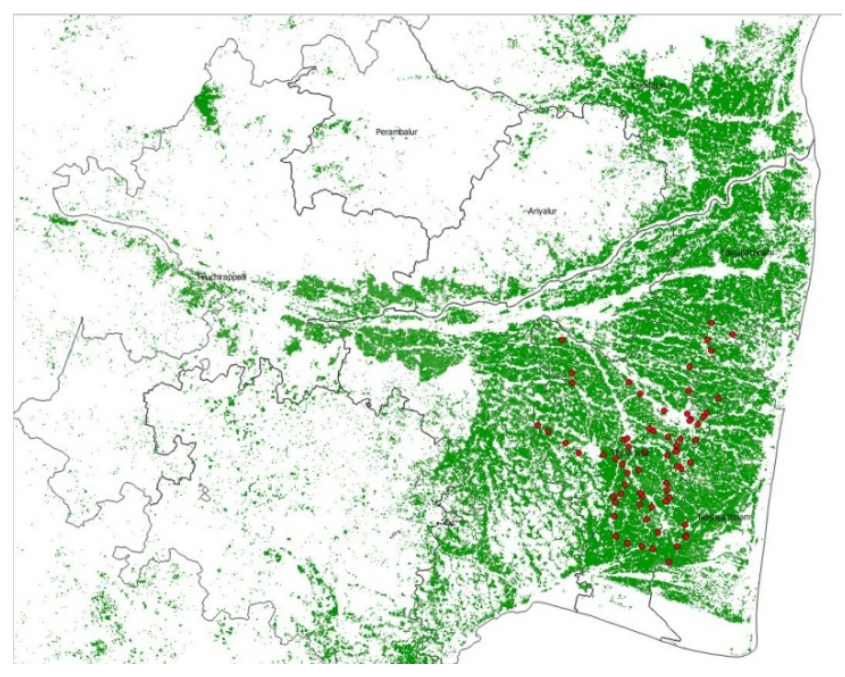

Fig. 1. Rice area map - Cauvery delta region, TamilNadu, India

Table 1.Summary of site validation visits, rice area and accuracy assessments.

\begin{tabular}{|l|l|r|r|c|c|}
\hline $\begin{array}{c}\text { Site } \\
\text { No. }\end{array}$ & $\begin{array}{c}\text { Districts of } \\
\text { TamilNadu }\end{array}$ & \multicolumn{1}{c|}{$\begin{array}{c}\text { Validation } \\
\text { points }\end{array}$} & $\begin{array}{c}\text { Rice } \\
\text { area (ha) }\end{array}$ & $\begin{array}{c}\text { Accuracy } \\
\text { (\%) }\end{array}$ & Kappa \\
\hline 1 & Thanjavur & 111 & 112246 & 92.6 & 0.81 \\
\hline 2 & Thiruvarur & 106 & 134113 & 94.2 & 0.88 \\
\hline 3 & Nagapattinam & 83 & 110668 & 90.3 & 0.81 \\
\hline 4 & Tiruchirapalli & 78 & 27226 & 89.1 & 0.78 \\
\hline 5 & Cuddalore & 102 & 86712 & 92.4 & 0.82 \\
\hline 6 & Other districts & 1185 & 601321 & $86.9-92.5$ & $0.76-$ \\
\hline & $\begin{array}{l}\text { Points and } \\
\text { area (ha) }\end{array}$ & $\mathbf{1 6 6 5}$ & $\mathbf{1 0 7 2 2 8 6}$ & & 0.83 \\
\hline
\end{tabular}

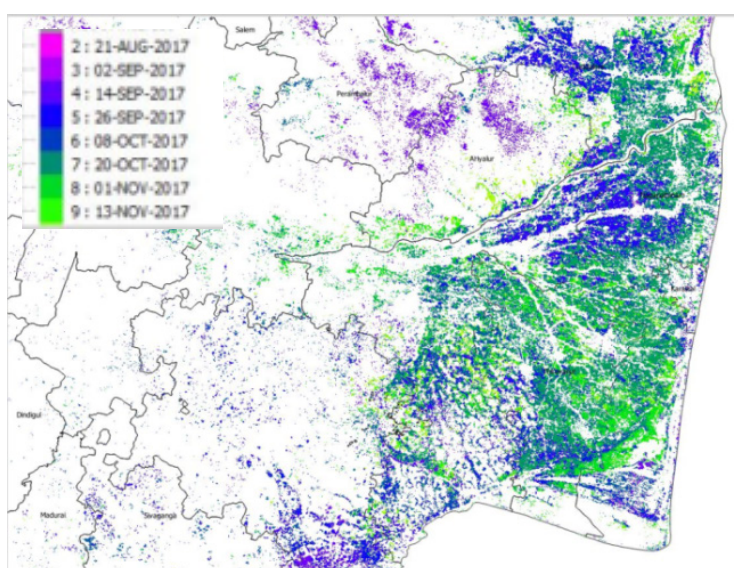

Fig.2. Rice SoS map 2017-18- Cauvery Delta

Table 2. District wise rice area statistics (ha) at 12 days interval derived from start of season maps (2017)

\begin{tabular}{|l|r|r|r|r|r|r|r|}
\hline \multicolumn{1}{|c|}{ District } & 26 Sep & 08 Oct & 20 Oct & 01 Nov & 13 Nov & 25 Nov & $\begin{array}{c}\text { Rice } \\
\text { area(ha) }\end{array}$ \\
\hline Cuddalore & 9723 & 15918 & 14328 & 30784 & 5698 & 3945 & 86712 \\
\hline Nagapattinam & 14480 & 8913 & 11160 & 52499 & 10644 & 2641 & 110668 \\
\hline Thanjavur & 20988 & 10667 & 17204 & 25024 & 11573 & 4522 & 112246 \\
\hline Thiruvarur & 7595 & 9021 & 14277 & 55370 & 19303 & 2893 & 134113 \\
\hline Ramanathapuram & 32710 & 27459 & 44185 & 11706 & 6901 & 745 & 123876 \\
\hline Sivaganga & 3237 & 3365 & 5568 & 2618 & 2095 & 1184 & 68509 \\
\hline Pudukottai & 10801 & 13547 & 6803 & 2205 & 1890 & 897 & 45243 \\
\hline Ariyalur & 2197 & 722 & 1987 & 1881 & 2384 & 3307 & 16588 \\
\hline Perambalur & 5038 & 152 & 1223 & 489 & 313 & 112 & 7385 \\
\hline Karur & 111 & 335 & 1027 & 649 & 1040 & 656 & 8402 \\
\hline Tiruchirapalli & 112 & 522 & 1273 & 2305 & 4559 & 3075 & 27226 \\
\hline Thiruvallur & 13313 & 18626 & 5884 & 6787 & 1090 & 646 & 50083 \\
\hline Kancheepuram & 10800 & 2246 & 1325 & 7469 & 7092 & 3923 & 54614 \\
\hline Dindigul & 8276 & 174 & & 681 & 72 & 69 & 9743 \\
\hline Thiruvannamalai & 39540 & 6773 & 9057 & 629 & 12260 & 5227 & 105286 \\
\hline Villupuram & 17028 & 7393 & 20316 & 5064 & 27221 & 13519 & 111592 \\
\hline Total & 195948 & 125833 & 155617 & 206160 & 114135 & 47360 & 1072286 \\
\hline
\end{tabular}

\section{Rice yield estimation}

Incorporation of LAI from SAR into process-based rice yield simulation using ORYZA effectively captured spatial yield distribution during 2017-18 Samba season in Tamil Nadu, India as shown in Fig. 3. The end of season yield estimates for rice derived integrating remote sensing products and ORYZA crop growth model were in the range of 2022 to $5494 \mathrm{~kg} \mathrm{ha}^{-1}$ in the delta districts of Tiruchirapalli, Thanjavur, Tiruvarur, Nagapattinam, Ariyalur and Perambalur showing the capability of the methodology to capture spatial variations in rice yield. Further the methodology was effective in capturing crop failures resulting in poor yields of 214 to $255 \mathrm{~kg} \mathrm{ha}^{-1}$ in Ramanathapuram, Sivaganga and Pudukottai districts, where drought has caused yield reductions. 


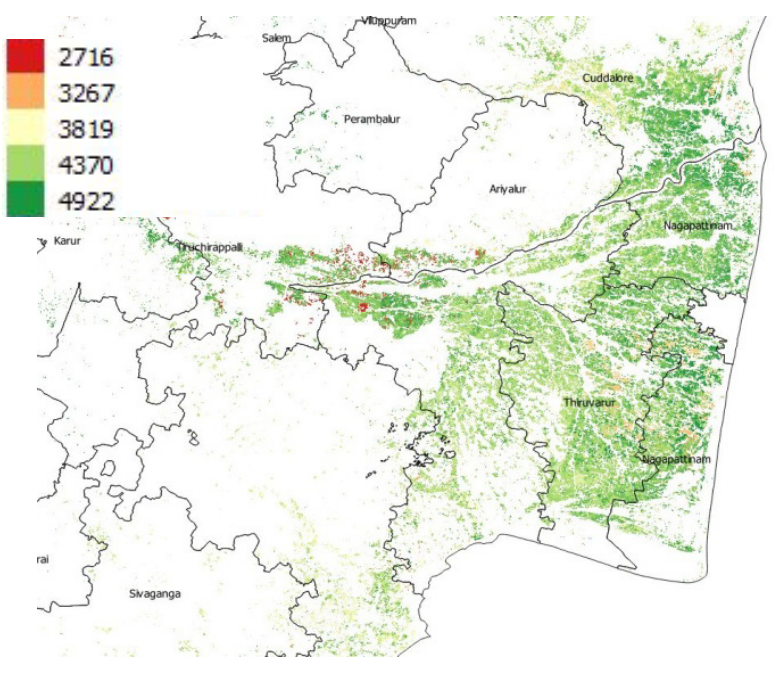

Fig. 3. Rice Yield map 2017-18- Cauvery Delta

The validation of the spatially generated rice yield was carried out in 100 locations of Tiruvarur district by comparing with the observed yield. At the monitoring sites the agreement was found to be from 81 to 96 per cent with the mean agreement of 86.2 per cent for rice yields. The average errors as computed by RMSE and NRMSE were $403.9 \mathrm{~kg}$ ha- 1 and 13.8 per cent respectively.

\section{Remote sensing for Prevented and Failed sowing}

A detailed map of the rice growing area detected from the analysis of Sentinel $1 \mathrm{~A}$ data acquired during the monitored season was used to generate rice area statistics every 12 days at village level. Normal area sown figures for the notified villages were compared with the villagewise area generated using SAR data and the villages were identified for invoking prevented sowing wherever the area sown was less than $25 \%$ with the reduction caused by delayed onset of monsoon or water release from canal preventing the farmers from sowing or planting.

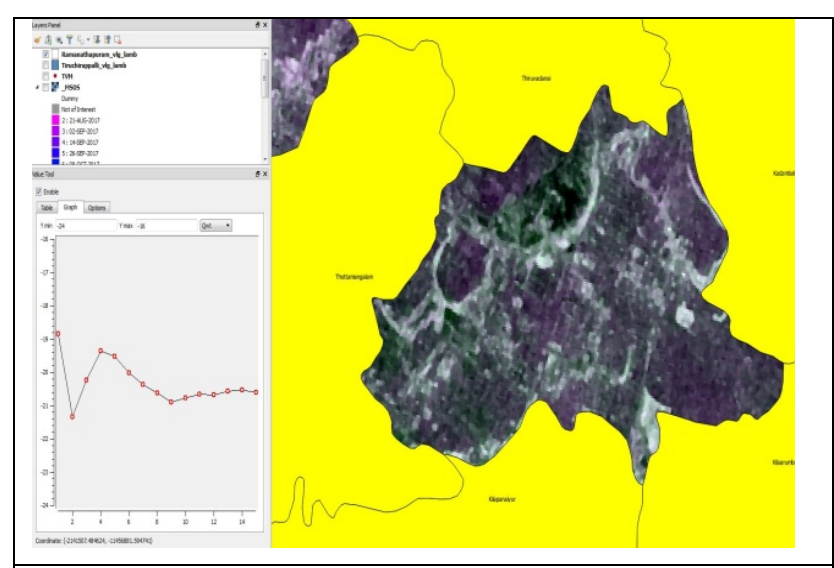

Fig. 4a. Temporal signature for Failed sowing

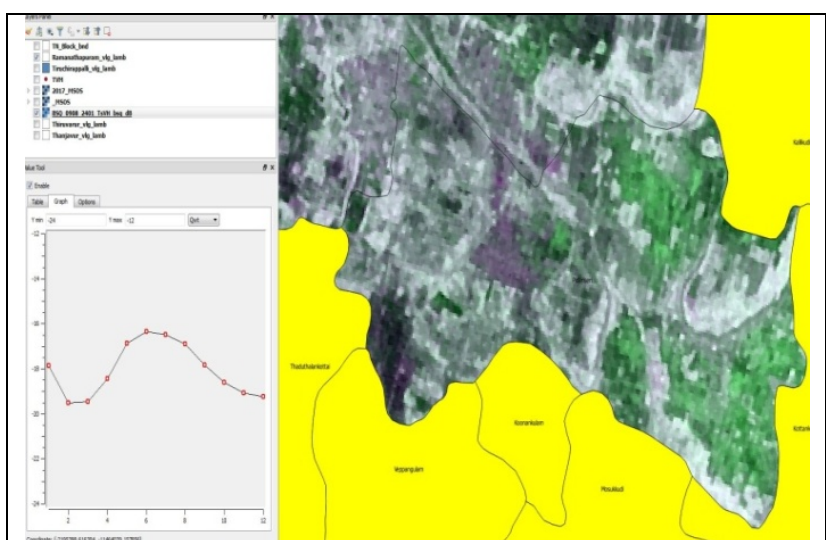

Fig. 4b. Temporal signature for Total Crop Failure

Backscattering signature for crop field were generated using the $\mathrm{dB}$ stack derived from 11 date SAR images and the date of crop failure was assessed and the villages were identified for failed sowing (within thirty days after sowing) or total crop failure (beyond 30 days) as depicted in Fig. 4.

Table 3. Number of villages identified for Prevented/Failed sowing and Total crop failure

\begin{tabular}{|c|r|r|r|}
\hline Year & $\begin{array}{c}\text { Villages } \\
\text { Monitored }\end{array}$ & PS/FS & $\begin{array}{c}\text { Crop } \\
\text { Failure }\end{array}$ \\
\hline $\mathbf{2 0 1 7 - 1 8}$ & 1277 & 246 & 214 \\
\hline $\mathbf{2 0 1 6 - 1 7}$ & 2516 & 529 & 821 \\
\hline
\end{tabular}

SAR products and yield information were used to meet the requirements of PMFBY crop insurance scheme in Tamil Nadu and helped in identifying or invoking prevented/failed sowing in 529 villages and total crop failure in 821 villages. In total 303703 farmers were benefitted by this technology in getting payouts of INR 9.94 billion through crop insurance. The satellite technology as an operational service has helped in getting quicker payouts and also to maximize the compensation which was due for the farmers ensuring the social protection and climate resilience.

\section{References}

Bouvet, A., T. Le Toan, and N. Lam-Dao. 2009. "Monitoring of the Rice Cropping System in the Mekong Delta Using ENVISAT/ASAR Dual Polarization Data." IEEE Transactions on Geoscience and Remote Sensing 47: 517-526. doi:10.1109/TGRS.2008.2007963.

Dwivedi, R. S., B. R. M. Rao, and S. P. S. Kushwaha. 2000. "The Utility of Day-And-Night Observation and CloudPenetration Capacity of ERS-1 SAR Data for Detection of Wetlands." Geocarto International 15: 7-12. doi:10.1080/10106040008542134. 
Ferencz, C., P. Bognár, J. Lichtenberger, D. Hamar, G. Tarcsai, G. Timár, and I. Ferencz Árkos. 2004. "Crop Yield Estimation by Satellite Remote Sensing.” International Journal of Remote Sensing 25: 4113-4149. doi:10.1080/01431160410001698870.

Gumma, M. K., P. S. Thenkabail, A. Maunahan, S. Islam, and A. Nelson. 2014. "Mapping Seasonal Rice Cropland Extent and Area in the High Cropping Intensity Environment of Bangladesh Using MODIS 500m Data for the Year 2010." ISPRS Journal of Photogrammetry and Remote Sensing 91: 98-113. doi:10.1016/j.isprsjprs.2014.02.007.

Holecz, F., M. Barbieri, F. Collivignarelli, L. Gatti, A. Nelson, T. D. Setiyono, M. Boschetti, et al. 2013. "An Operational Remote Sensing Based Service for Rice Production

Homma, K., M. Maki, and Y. Hirooka. 2017. "Development of a Rice Simulation Model for Remote- Sensing (SIMRIW-RS)." Journal of Agricultural Meteorology 73 (1): 9-15. doi:10.2480/agrmet.D-14- 00022.

Huke, R. E., and E. H. Huke. 1997. Rice Area by Type of Culture: South, Southeast, and East Asia, A Revised and Updated Data Base. Manila, Philippines: International Rice Research Institute.

Inoue, Y., and E. Sakaiya. 2013. "Relationship between XBand Backscattering Coefficients from High-Resolution Satellite SAR and Biophysical Variables in Paddy Rice." Remote Sensing Letters 4: 288-295. doi:10.1080/2150704X.2012.725482.

Inoue, Y., E. Sakaiya, and C. Wang. 2014. "Capability of CBand Backscattering Coefficients from High-Resolution Satellite SAR Sensors to Assess Biophysical Variables in Paddy Rice.” Remote Sensing of Environment 140: 257-266. doi:10.1016/j.rse.2013.09.001.
Le Toan, T., F. Ribbles, L. F. Wang, N. Floury, K. H. Ding, J. A. Kong, M. Fujita, and T. Korusu. 1997. "Rice Crop Mapping and Monitoring Using ERS-1 Data Based on Experiment and Modeling Results." IEEE Transactions on Geoscience and Remote Sensing 35 (1): 41-56. doi:10.1109/36.551933.

Lopez-Sanchez, J. M., J. D. Ballester-Berman, and I. Hajnsek. 2011. "First Results of Rice Monitoring Practices in Spain by Means of Time Series of TerraSAR-X Dual-Pol Images." IEEE Journal of Selected Topics in Applied Earth Observations and Remote Sensing 4: 412-422. doi:10.1109/ JSTARS.2010.2047634

Maki, M., K. Sekiguchi, K. Homma, Y. Hirooka, and K. Oki. 2017. "Estimation of Rice Yield by SIMRIWRS, a Model that Integrated Remote Sensing Data into a Crop Growth Model." Journal of Agricultural Meteorology 73 (1): 2-8. doi:10.2480/agrmet.D-14-00023.

Nelson, A., T. Setiyono, A. B. Rala, E. D. Quicho, J. V. Raviz, P. J. Abonete, A. A. Maunahan, et al. 2014. "Toward an Operational SAR-based Rice Monitoring System in Asia: Examples from 13 Demonstration Sites across Asia in the RIICE Project”. Remote Sensing 6: 10773-10812. doi:10.3390/rs61110773.

Oh, Y., S. K. Hong, Y. Kim, J. Y. Hong, and Y. H. Kim. 2009. "Polarimetric Backscattering Coefficients of Flooded Rice Fields at L- and C-Bands: Measurements, Modeling, and Data Analysis." IEEE Transactions on Geoscience and Remote Sensing 47: 2714-2721. doi:10.1109/TGRS.2009.2014053.

Suga, Y., and T. Konishi. 2008. "Rice Crop Monitoring Using $\mathrm{X}, \mathrm{C}$ and L Band SAR Data." SPIE Remote Sensing Proceedings 7104. Remote Sensing for Agriculture, Ecosystems, and Hydrology X 710410. doi:10.1117/12.800051. 